\title{
Rise of Digital Humanitarian Network (DHN) in Southeast Asia: Social Media Insights for Crisis Mapping in Disaster Risk Reduction (DRR)
}

\author{
Umber Nazir*, Noralfishah Sulaiman, Sheikh Kamran Abid \\ KANZU Research: Resilient Built Environment (RBE), Faculty of Technology Management and Business, Universiti Tun \\ Hussein Onn Malaysia, Batu Pahat 86400, Malaysia
}

Corresponding Author Email: hp180123@siswa.uthm.edu.my

https://doi.org/10.18280/ijsse.110509

Received: 3 June 2021

Accepted: 29 September 2021

\section{Keywords:}

digital humanitarian network, social media, crisis mapping, crisis management, Facebook, disaster risk reduction

\begin{abstract}
Digital technologies and big data speedily change humanitarian crisis response and transform the processes from traditional to digital. Digital Humanitarian Network (DHN) for disaster risk reduction (DRR) using crisis mapping of the vulnerable population is becoming increasingly common during any disaster response process. To get the information and provide in time support, the critical Source of data is social media. In Southeast Asia, Facebook is the most used social media platform. Communities often rely on social media to seek in time assistance and guidance. Emerging social media and networks are remarkably well-compatible with intelligent data-centric systems, which foster an effective disaster management plan under disaster scenarios. During previous disasters in Southeast Asia, it was believed to be the fastest response medium. However, validation is essential to obtain important data, and after years of research, there are still many undiscovered features of social media that can be used in emergencies. This paper aims to determine Southeast Asian countries' readiness to utilise social media for DRR activities and understand the criteria of DHN by integrating crisis mapping. A qualitative research design is applied to gain an insight into the humanitarian disaster network for disaster risk reduction. Data were collected through document analysis. I argue that digital humanitarians can offer a unique combination of speed and safe access while escaping some of the traditional constraints of the aid-media relationship. The study concluded that DHN provides a collaborative environment for the organizations to collaborate and act fast to assist.
\end{abstract}

\section{INTRODUCTION}

Asia, especially Southeast Asia, is a complex area with a wide range of terrains and ecosystems, ranging from the mountain tops and plains of Southeast Asia's great rivers to the Malay Archipelago's numerous islands. In addition, Asia is the most affected area of the world by natural disasters. Through this difficult period of crisis, the experience can offer insight into how people in these Asian regions have dealt with the impacts and shifts imposed by external influences, giving the country a form and spirit. Social media includes websites, social bookmarking, social networking, message boards, collaborative document creation, and the sharing of audio, visual, and video files [1]. Communication, in which information is traded by persons, listeners, associations, and other public places [1]. It is defined by mutual contact, in which knowledge is shared among individuals, listeners, organisations, and other public places. Cell phones and social media networks are becoming increasingly common, to the point that they are regarded as a global superpower.

The most challenging task is confronting organisations once a threat arises for the lack of a collaborative solution between various organisations. These independent agents are fully engaged in the decision-making process $[2,3]$. The most challenging challenge confronting organisations once a threat arises the lack of a collaborative solution between various organisations. These independent agents are fully engaged in the decision-making process [4]. Cooperation and teamwork between multi-agency and other member organisations necessitated relevant information to create a common forum or effective crisis management plan. Amid a tragedy, time is of the essence, and authorities must respond efficiently and adequately [5]. Therefore, it is crucial to comprehend any element of risk and its components in order to carry out an effective DRR.

Emerging innovations such as disaster mapping, remote sensing, and Geographic Information Systems (GIS) are becoming increasingly important in disaster management [6]. In addition, social media platforms such as Facebook and Twitter are often used to monitor community reactions to disasters and public response behaviour. Due to emergency management and reaction in any hazardous situation, these software and social media applications help coordinate and monitor the risk response process [7]. In this paper, the researcher looks at recent risk patterns and applications.

The Digital Humanitarian Network is a consortium of volunteer and technical communities whose mission is to leverage digital networks to support 21st-century humanitarian response. The group provides an interface between formal humanitarian organizations and informal yet skilled and agile volunteer and technical professionals.

DHN puts groups that have existed and worked for years under one umbrella and provide one channel for conventional responders to access the organization. DHN can make it 
simpler for the organizations to define collaboration projects with V\&TC members. DHN Creates substantial intrusions in the way aid organisations leverage technology and power of V\&TCs [8]. It is the best way to support Humanitarian Organisations (HO) in their disaster response efforts around Southeast Asian countries [9]. The DHN consists of several solution team members, who map the crisis with social media data readily accessible to the community by using the networkenabled on demand of any country, the related solution teams or V\&TCs.

In the late 2000 s, one social media approach to a crisis was crisis visualisation. Patrick Meier, a catastrophe mapper, activist, and digital humanitarian, launched the first highly known case in 2010 when he published a crisis map an hour after the earthquake. Unfortunately, it was not part of a wellcoordinated, strategic emergency strategy. Following the publication of Meier's map in 2010, crisis mapping became familiar. In 2015, situation mapping was often used to provide real-time information after natural disasters and terrorist attacks [10].

Planning and flexible incident response to events as they occur, often in unexpected ways, is a vital feature of crisis analysis. A country's ability to work economically can be harmed by the swirling impact of a crisis and do considerable damage to its population, structures, properties, and prestige. The proliferation of social media platforms has significantly altered the world of disaster management over time, with opportunities for social activism now becoming realities. Organizations will now publicise, collect, and analyse information more effectively and thoroughly using freely accessible software resources, including web chat forums and news aggregators. Unfortunately, although social media has the potential to save a crisis from spiralling out of control, it also has the potential to exacerbate an existing situation.

For crisis analysis, crisis response may be split into three stages of emergency management. Figure 1 shows the diagram of the 3 phases of crisis management.

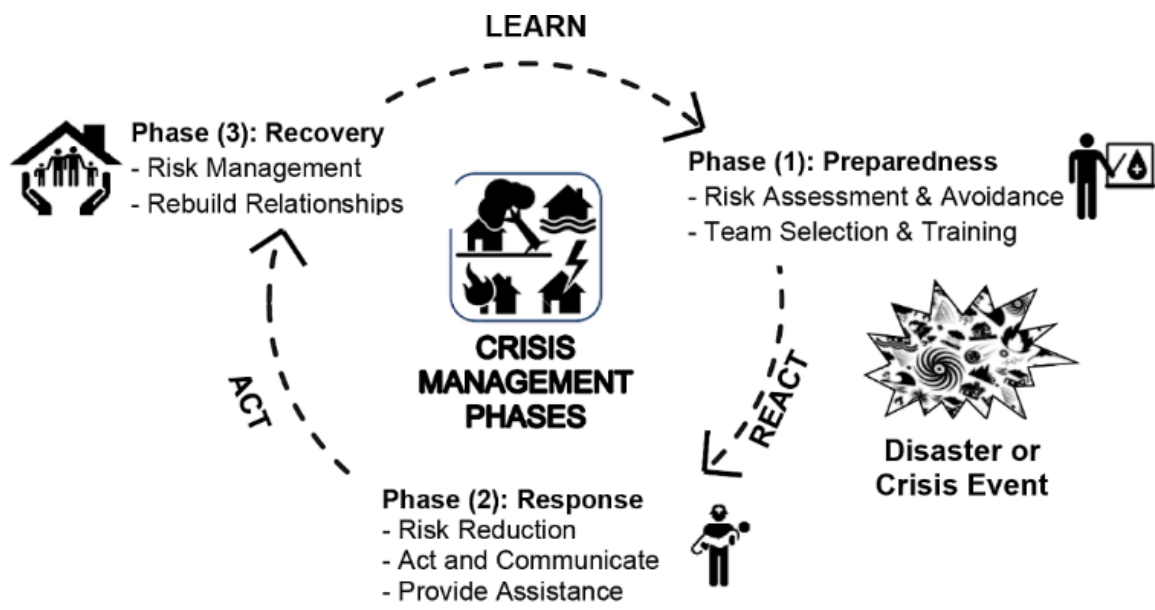

Figure 1. Phases of Crisis Management, Source: The Researcher, 2021

Phase 1: Preparedness. During the crisis preparedness phase, crisis mapping focuses on proactive activities to figure out how to reduce the expected risks that can cause the crisis. Acknowledging that all disasters and situations cannot be prevented, there has to be an equivalent emphasis on crisis mapping and training their mapper team [11]. Jeannette Sutton, a disaster sociologist and a senior research scientist who studied social media in crisis \& disaster at the University of Colorado, said that Depicting an effective social media strategy and modifying it to fit an emergency, though, is a critical part of preparedness planning [12]. Therefore, in this crisis management phase, the tasks are more towards risk assessments \& avoidance and, team selection \& training.

Phase 2: Response. During the crisis response phase, crisis mapping focuses on the swiftness and effectiveness of the preliminary response [11]. The approach is to react to the crisis event accordingly. It is high time that organisations become aware of the situation quickly to act adequately during and after the crisis. The correct use of social media platforms and tools will be necessary during this phase to involve community networks to collect, evaluate and disseminate information in a suitable way. The tasks in this phase are to reduce risk, act, communicate, and provide assistance to the community timely and effectively.

Phase 3: Recovery. After the imminence of response has passed, the crisis recovery phase requires long term planning and assistance to restore the condition to normalcy and even build back better [11]. During the crisis recovery phase, the tasks to focus on are risk management, rebuilding relationships, learning from the previous crisis event, and planning accordingly.

\section{RESEARCH PROBLEM}

Disasters are increasing due to complicated connections between human activity and 'natural hazards [13], which are a rising threat to the progression and prosperity of countries, societies and communities across the Southeast. However, disasters risks present within the development, evolving procedures mainly determine the community's exposure, reserves and resources to hazards, vulnerability to experiencing damage and ability to deal with and change to new conditions [14]. This paper provides a review of population and social media user statistics in Southeast Asia. It also discusses the importance of the Digital Humanitarian Network (DHN) in reducing the disaster risk using crisis mapping from community involvement through social media and internet usage around the countries. Crisis mapping emerged in 2010 and is commonly used for real-time updates. Disaster professionals, policymakers and practitioners use the crisis mapping tool to increase situational awareness and map 
the information and individual's location in real-time.

Southeast Asia is one of the highly disaster-prone regions of the world. Almost all natural hazards and disasters occur there; meteorological, hydrological, climatological, and geophysical [15]. In Figure 2 number of disasters mention for every country in Southeast Asia. The ASEAN Coordinating Centre for Humanitarian Assistance on disaster management
(AHA Centre) report mentioned that Indonesia has the highest number of disasters due to its geographical location on the 'Ring of Fire'. Countries like Malaysia, the Philippines, Thailand and Vietnam are also hit by disasters almost every year due to monsoonal seasons and heavy rainfall. As a whole, 1380 disasters occurred in Southeast Asia during 2012 - 2018 [16].

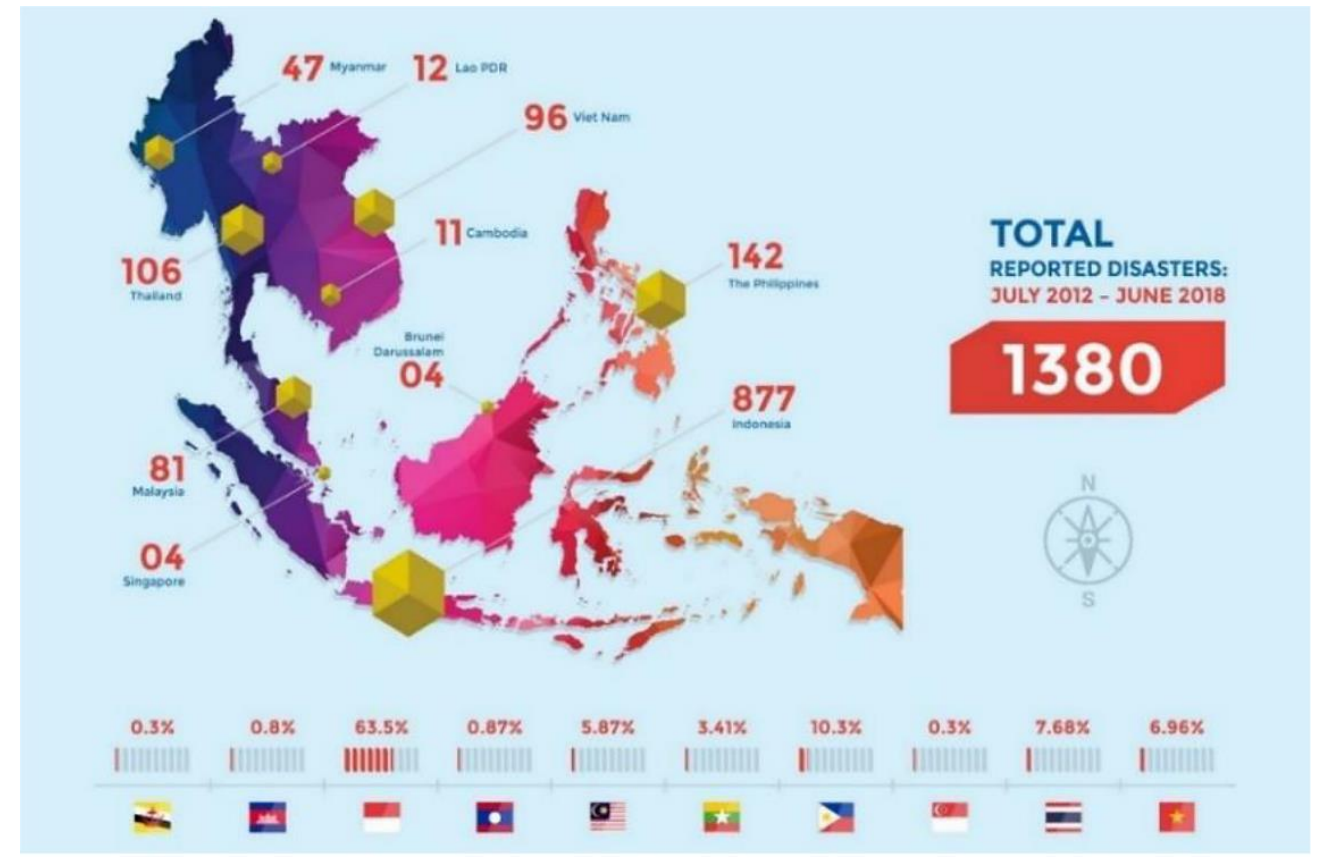

Figure 2. Total disasters (tropical, flood, landslide) reported in Southeast Asia [16]

Climate change has put Indonesia, the Philippines, and Vietnam vulnerable mainly. Long-term droughts, a rise in the rate of extreme weather conditions, and intense rainfall resulting in significant flooding are only a few indicators of climate change's effects [17]. According to the latest report on ASEAN Risk Monitor and Disaster Management Review (ARMOR) issued by the ASEAN Coordinating Centre for Humanitarian Assistance on Disaster Management (AHA Centre) in March 2019, floods affected 57 percent of the total population ASEAN from 2012 to 2019. Malaysia had the highest percentage of people exposed to floods among all ASEAN countries [18].

Total economic loss (damage) from 1970 to 2015 can be seen in Figure 3; every year, the cost of damage increases, alarming for Southeast Asia. Economic loss and loss of life, resources, and other joint losses of the community and nation.

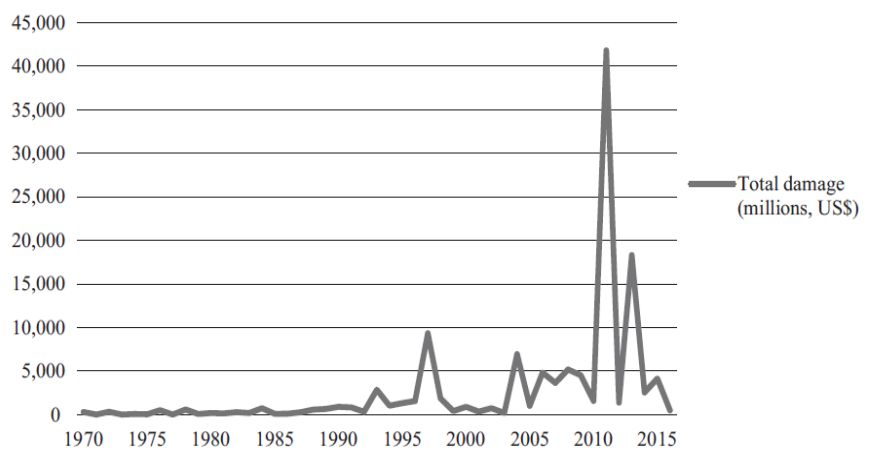

Figure 3. Total economic impact (damage) from 1970 to 2015 in Southeast Asia [19]
Humanitarian organizations reported several benefits with technologies, especially saving lives, costs and time [20]. With the rise of technology and IR 4.0, new systems are introduced in DRR and provide aid to the communities at the disaster. Digital Humanitarian Network (DHN) is one of them. DHN activated at the disaster response phase to give support and assistance, through technical and volunteer teams worldwide, to the community and organizations to act accordingly and save lives and damages in less time. Through DHN, the volunteer and technical communities map all the data of the vulnerable people and places from the hazard area to assist the aid organizations in acting timely and effectively. Without DHN, the disaster response would be slow and effective because time is the most crucial variable to manage during a disaster event. Also, the data provided by the DHN community is reliable and fast rather than other conventional ways. Therefore, this digital way of disaster risk reduction is effective and efficient. As you can see in the literature review, the previously activated DHN helped a lot during the disaster events. The key component of DHN is the data collection and selection from social media and other internet sources, which is already there, so this digital form of DRR during different phases can be implemented and utilised for the betterment of the communities and nations.

\section{LITERATURE REVIEW}

\subsection{Digital Humanitarian Network (DHN)}

People around the globe who use online events to promote science and relief operations, regardless of their physical 
environment, are digital humanitarians. One of the most common approaches to digital humanitarianism is crisis mapping [8]. For example, during the Haiti earthquake, via their emails, Facebook posts, and other direct updates on social media, online volunteers or helpers locate victims. The data they gathered was organised and put together online to help disaster-response agencies determine where and when to provide support or relief. The layers of satellite imagery are generated by data gathered from social media users with the help of crisis mappers to assess road conditions in the hazard area, providing timely information for aid organizations. Relevant information can be obtained even more efficiently by DHN than by the slow and inconsistent information available on the ground [8]. When it comes to disaster management, digital humanitarianism has an added benefit: it fosters a sense of community and partnership. These DH, known as the Helper \& Professional Groups, were established after the
Haitian tragedy (V\&TCs). They've participated in a variety of global conflicts.

V\&TC had some reservations about functional design, data consistency, and precision to add more coordination and cooperation. To address these issues, the UN for the Coordination of Humanitarian Affairs (UN-OCHA) developed the DHN. The DHN acts as a link between volunteer networks and the humanitarian system. In crisis response situations, DHN also functions as a global Operational Delivery Network, allowing formal humanitarian organisations (FHO) to access the extensive networks and resources of 18 member V\&TCs. As a consequence, it can be used as a model for productive collaboration between dispersed, digitally enabled citizen networks and formal international organisations (FIO). Figure 4 depicts the operation of the DHN, which was the first DHN to be built, including 11 organisations.

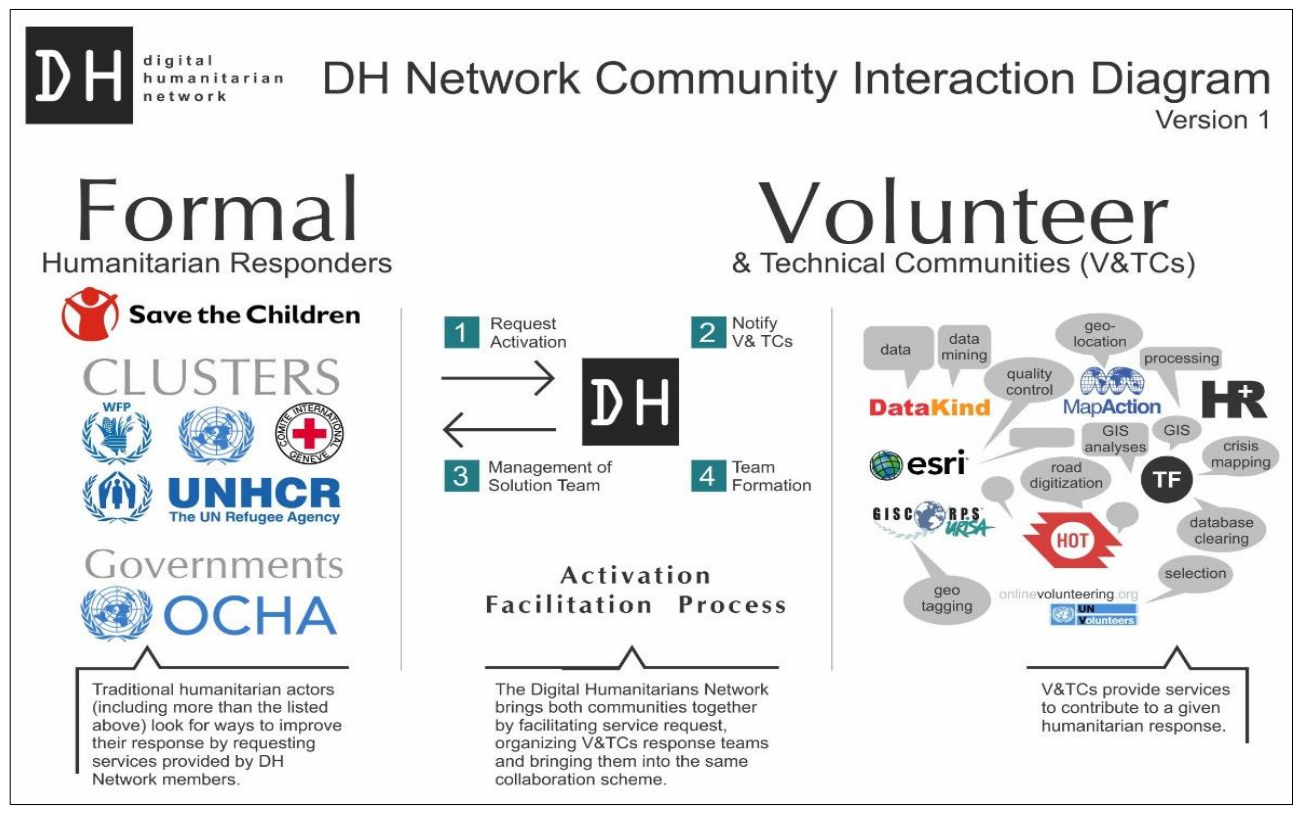

Figure 4. DHN community interaction diagram version 1 Source: [8]

\subsubsection{Criteria of a digital humanitarian network}

The researcher gathers the criteria of DHN from different sources on what is DHN, why do we need that, and how does it work. Figure 5 describes the brief criteria for DHN.

\subsubsection{Previous DHN activated for crisis mapping in Southeast} Asia

(1) Typhoon Pablo 2012 (Philippines): UNO for the Coordination of Humanitarian Affairs (OCHA) requested for the activation of the DHN on December 5, 2012, when Typhoon Pablo Strike Philippines, to check the real-time effects and damage by the typhoon and collect tweets from the residents regarding typhoon. Data from these tweets to identify images, video and geolocating to develop real-time maps of dislocated vulnerable, deaths, damaged fields, destroyed bridges and pathways [21]. The V\&TC teams hunted over 21,000 social media messages in 24 hours after the disaster for relevant photos and videos. Results were collected and arranged in an organised database. The Solution team used several methods, from automatic algorithms to micro-tasking through the PyBossa Platform. They used the Geofeedia platform to detect all appropriate print media, either pictures or videos geotagged by users. A map comes from only data gathered from social media analytics, released by DHN enabled by UN OCHA requested by the Philippines [9] as shown in Figure 6.

(2) Super Typhoon Yolanda 2013 (Philippines): After super typhoon Yolando struck the Philippines, OCHA was asked to activate DHN facilities once more. Yolando was the worst of all prior storms, inflicting the most damage in history. This typhoon in the Philippines caused 6,300 reported casualties, and about 2.3 million citizens were anticipated to fall beneath the poverty line. OCHA used the same services as before in 2012 to map the social media data using different platforms and the help of solution teams [22]. Several crisis mapping communities work together: OpenStreetMap, Standby Task Force (SBTF), DHN by UNOCHA and GIScience Research Group, Ushahidi and micro-mappers platform [23]. A crisis like Typhoon Yolando shows that humanitarians are progressively using communication tools: radio, mobile phones, and social media platforms to retrieve, connect and spread information that may help in saving lives or make a better living. Typhoon survivors also used Google's Free crisis tool, Google Person Finder [22], to post and seek their loved ones. The crisis mapping of Typhoon Yolando is shown in Figure 7. 


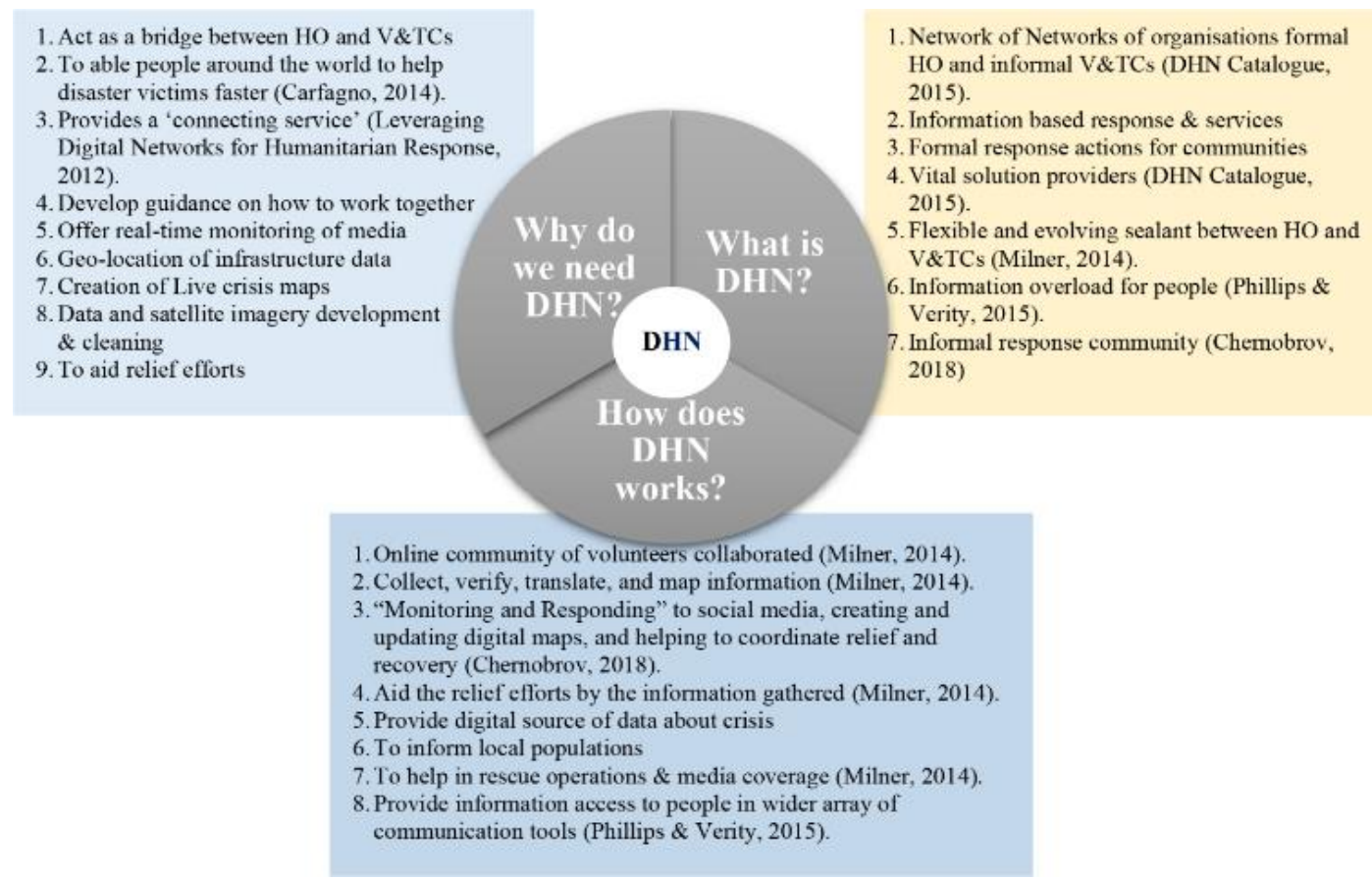

Figure 5. Digital Humanitarian Network (DHN) Criteria for What, Why and How - Source: The Researcher, 2021

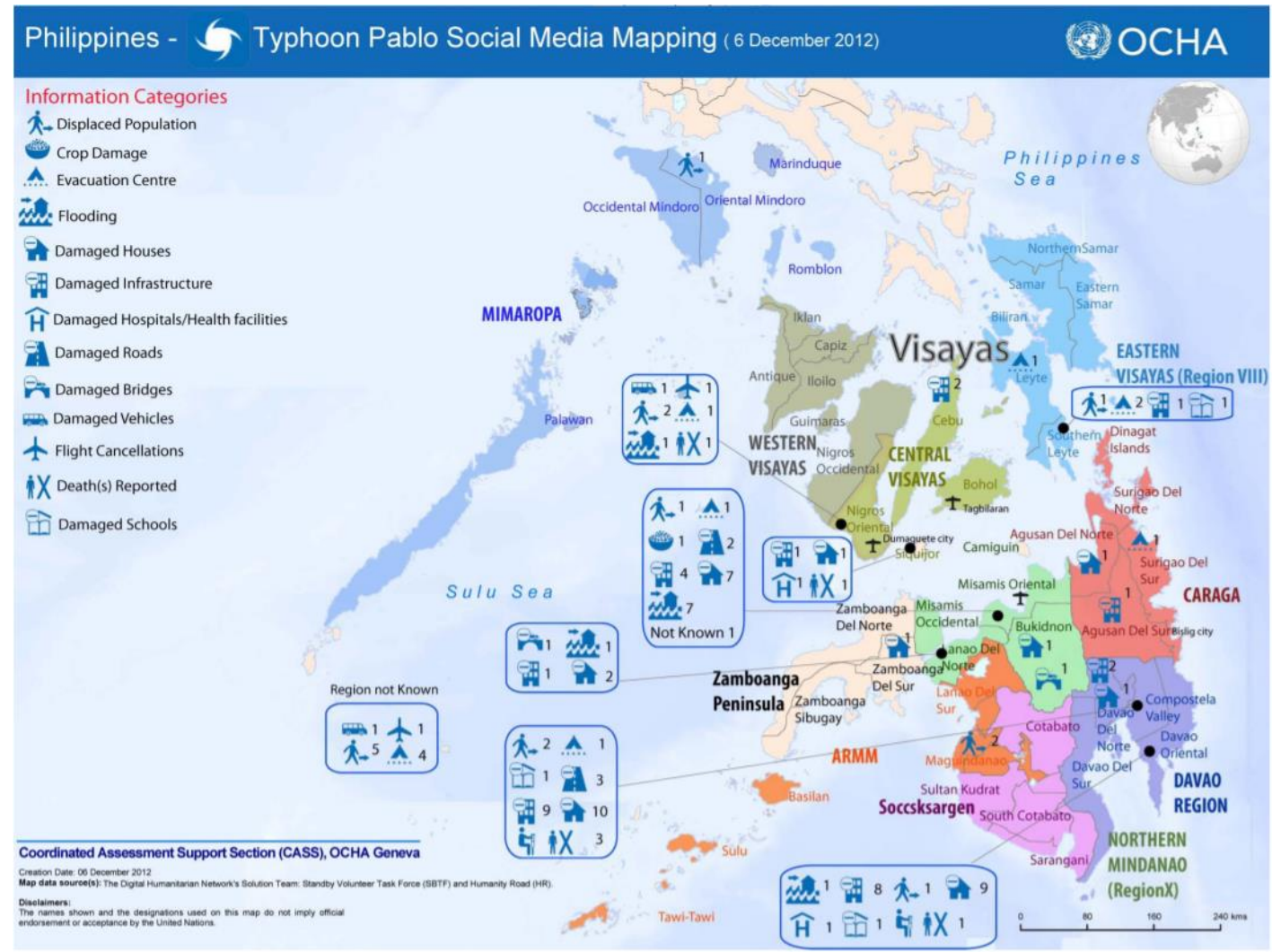

Figure 6. OCHA social media Typhoon Pablo crisis map. Source: [9]

(3) Nepal Earthquake in 2015: The government of Nepal has announced an emergency after the 7.8 scaled magnitude earthquake hit the country on April 25, 2015, more than 8,800 death casualties and destroyed nearly 600,000 houses in rural districts $[24,25]$. Nepal humanitarian response services were activated by OCHA, HumanityRoad, Kathmandu LivingLabs (KLL) and several others in 2015 for different periods to help Nepal combat the crisis. Also, the people of Nepal use other digital humanitarian technologies and platforms to help the country. Digital humanitarians are among the most modern technology. Taskforce teams bring together the humanitarian response under enhanced connectivity provided through the ever-increasing adaption of electronic/digital devices by many people worldwide [26]. In addition, the Humanitarian UAV Network (UAViators) has been activated and used to find, mobilise and organize UAV assets \& teams for crisis mapping to help Nepal [10]. Nepal Earthquake 2015 crisis mapping is shown in Figure 8. 


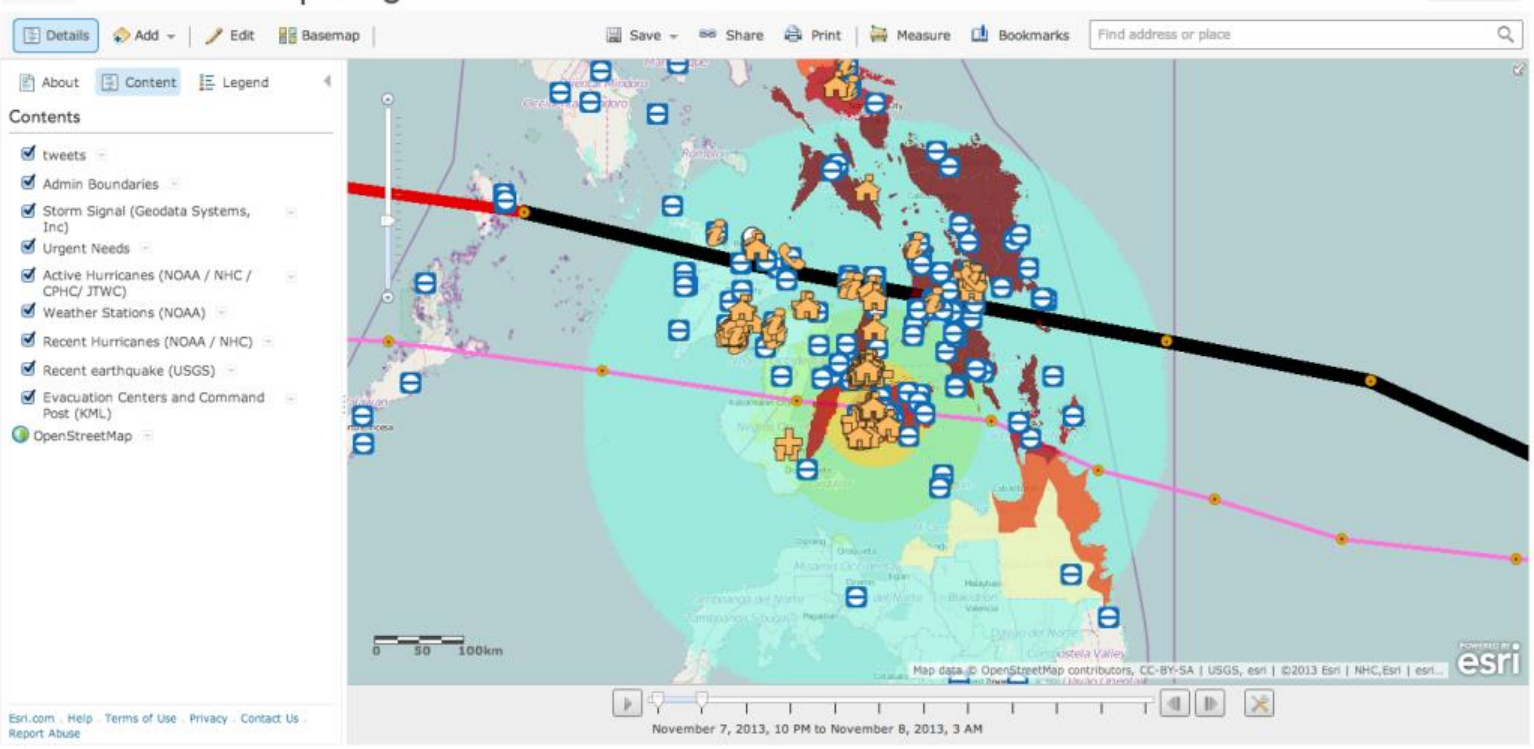

Figure 7. Crisis mapping of Typhoon Yolando using Twitter data, Source: [24]

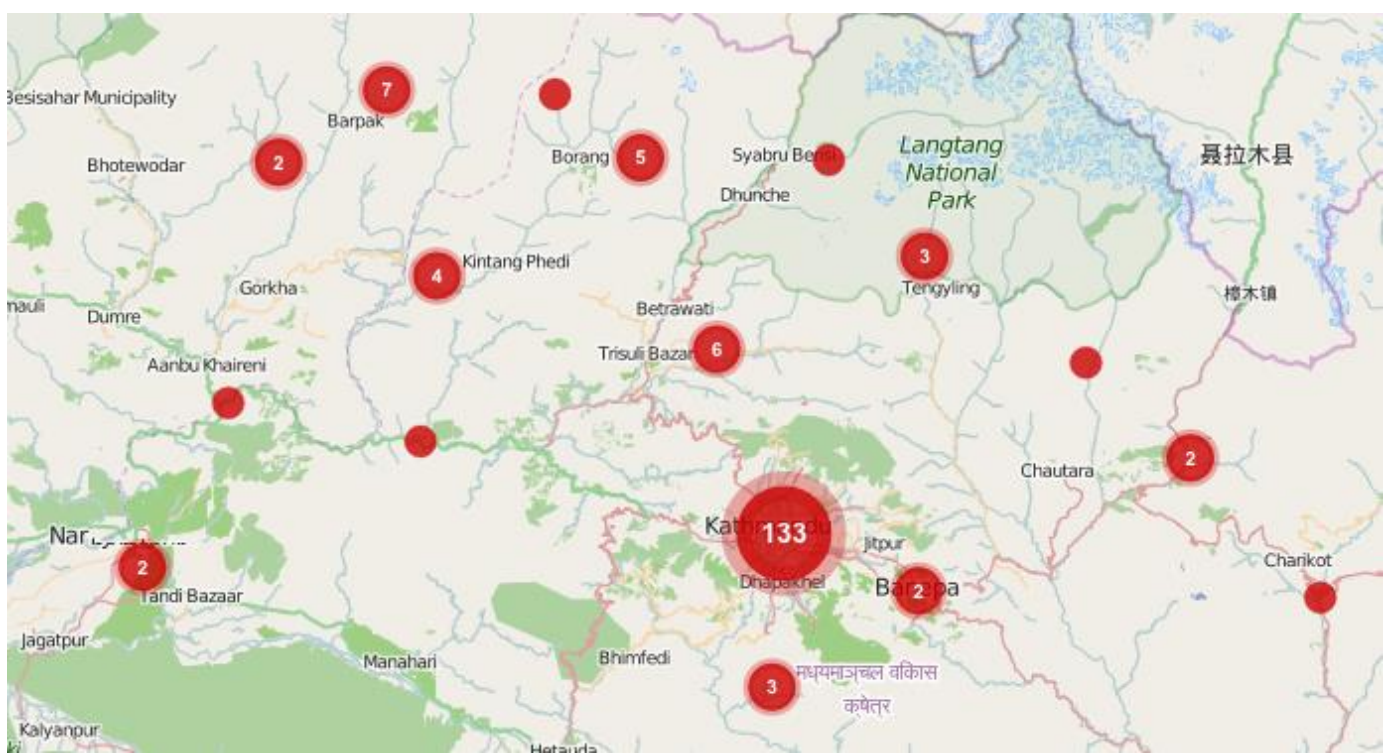

Figure 8. Nepal Earthquake 2015 crisis map of reports Source: [26]

\subsection{Role of social media}

Social network voice is a voice that first emerged in the twentieth century and refers to those who use smartphone technologies and online content. A voice that is provided to certain people that usually don't have one. Social networking is a forum that allows diverse people to interact and exchange their opinions, thoughts, and feedback with others efficiently and timely. With the aid of social media, people can more readily exchange information and views. During a disaster, social media has the potential to expose facets of the public's physiological, mental, and moral state of mind [27]. In any hazardous environment, it has a propensity to manage opinions, feelings and work efficiently. During a crisis, online social networking platforms like Twitter, Facebook, and Instagram can respond rapidly and play a key role in fixing the problem [28].

In times of crisis, geospatial technologies such as remote sensing and GIS and social media services will help tremendously and quickly [5] and provide real-time monitoring and decision support in terms of visualization and integration of mappings in crisis events [29]. In all stages of the emergency relief period, social media services have been very successful. Previous studies discovered success stories involving social network use and preparedness in emergency response. Social networking apps can also assist with a variety of health problems. The devastating earthquake in Haiti and cholera, dengue fever, and other fever outbreaks in Thailand and Indonesia are only a few examples of how social media has responded to earthquakes and other public issues [30].

\subsubsection{Social media \& disaster risk reduction}

Houston et al. [31] established fifteen essential uses of social media in disaster relief and discovered that social media provides a link for disaster information in multiple stages of disaster preparedness and recovery and information relevant to early alerts and coordination. Social media can detect a catastrophe incident by integrating community stakeholders' 
knowledge about the particular dangerous environment. The structure of social media shows that different features can be utilised in these processes and provide essential data through social media users.

During the disaster event, the social media broadcast the information just like a line, through which the stream of distributing information is quite prominent in volume and fast. The social media apps like Facebook \& Twitter provide key support to the people posting status, tweets \& comments and, with one click, share that information swiftly to the whole community and spread in the risk area. Imran et al. [32] described that during the disaster phases of preparedness and response, the organisations and other disaster agencies act promptly and considerably to provide assistance to the disaster affected beings and vulnerable communities in less time.

During crisis events (manmade disasters or natural disasters), millions of tweets on Twitter and status updates on Facebook appeared on social media platforms and similar on other apps [33]. It has been observed and shown that in any catastrophe situation, the public relies more on social media content, and the number of crises and people's trust in them has risen over time. Paul [33] examined how to distinguish between catastrophe-related and non-disaster-related information, as some applications automatically validate information when a disaster occurs. Paul [33] tested the authenticity of the relevant information from different social media apps. Moreover, He developed and evaluated the procedures to share that information and methods.

Alexander [1] also explained that how social media networks and these functions can be utilized. Also, He built an algorithm to monitor social media activities and examine user behaviour and perception towards information \& communication. The passage of data can be through mobile, laptops, or any other devices. The community can easily share information and opinions related to emergencies with the public.

During the 2010 Haiti earthquake's response process, it was evident that social media networks were engrossed in crisis management; people worldwide were studying and finding valuable details and knowledge about the Haiti earthquake through social media channels in record time.

Alexander and Paul [1,33] determined that social media emerged as a new platform for collecting intelligence and community activities. Social media has been studied in disaster as a general trend to analyse social interaction functions using the internet and other devices [34]. In all related research on this topic: the main themes discussed as, what are the functions of social networks and how they are used are:

(1) How to develop and use algorithms to enhance social networking;

(2) The extent of social network usage, how to identify users and their preferences; and

(3) The access of smart devices and social media to the user.

In addition, researchers looking into risk, crisis and disaster under the following themes:

(1) Social media usage, advantages and importance in disaster risk management;

(2) Front liners and reporters' views and opinions on social media and its integration with new communication techniques; and

(3) How social media interact with conventional sources of data and information.

There's a massive difference between the technical and social aspects of social media. The formation of a new social platform using different algorithms characterizes the previous media $[35,36]$. At the same time, further studies on the types of usage and two-way chat correlate to the new technology [37, 38]. Furthermore, the technology is used to study the messages' ratio and mode of dispersion [39]. Meanwhile, researchers work together during crisis events to develop algorithms and software for the efficient diffusion of messages through social media. For example, Plotnick et al. [40] and Reuter et al. [41] described more efficient approaches to classifying the uses and potentials of social media in crisis management.

Sutton et al. [42] briefly summarized the situation in social media regarding disaster risk reduction as:

"Our data suggest that social media support the influence of the existing public side information production and distribution. Due to the growing utility of social media and the ubiquity of peer-to-peer communications, we believe that a change in disaster management models will come about despite any failure to formally recognize these widely distributed and often strikingly well-organized information activities. However, we argue that simply letting these inevitable changes occur would result in needless delay, conflict and missteps. Instead, we call for efforts by public officials to consider how to align with peer-to-peer information exchange activities and to develop new conceptualizations of the information production and dissemination functions for disaster response." [42].

\section{RESEARCH METHOD}

This paper aims to understand the Readiness of Southeast Asian Countries' engagement in DHN technology and its usage for DRR. The countries in Southeast Asia are Malaysia, Thailand, the Philippines, Vietnam, Singapore and Indonesia.

According to Sulaiman [43], research methods can be divided into two approaches (1) Quantitative and (2) Qualitative. In this study, the researcher executed a qualitative research approach and employed a document analysis method to achieve the objective of this research. The researcher used content analysis based on secondary documents/reports. The nature of the one report, Digital ASEAN Statistics (20192020), is the statistical data of the users around southeast Asian countries about mobile, internet, and social media usage. Its results will be based on mobile, internet, and social media users around Southeast Asian countries.

Understanding the concept of DHN and the use of social media in Southeast Asian countries requires reviewing and deriving useful users' information through statistical reports and electronic reports by renowned organisations. Therefore, the Digital ASEAN Statistics website have been selected for data gathering from their reports. The research focuses on the readiness of Southeast Asian countries for the usage of DHN through social media and technology. At the same time, the purpose is documentary analysis, the data collected from the reports of Digital ASEAN Statistics. The data collected from this report are the total population, internet users, social media users, mobile users and social media penetration in southeast Asian countries. 


\section{RESULTS AND DISCUSSION}

The internet and social media are renovating the idea of disaster or crisis management for the world and Southeast Asia in particular. The data collected from Digital ASEAN Statistics from 2019 to 2020 is shown in the table below. Table 1 summarised the number of Internet, mobile and social media users from 2019 to 2020 in Southeast Asia. In the year 2019, the total population from Indonesia to Singapore decreases depending upon the geographic sites. Still, as you can see, the number of internet users, social media and social mobility is more than half of the population. In fact, in some countries, the penetration is almost $2 / 3 \mathrm{rd}$ of the population. By concluding the results from Digital ASEAN Statistics, the social media penetration in Southeast Asia is on average above $50 \%$, so the countries are ready to use DHN for crisis mapping to reduce disaster impacts in response activities.

Figure 9 and Figure 10 are derived from the above results featuring statistics about Southeast Asia's huge digital community, with many engaged social media users. Southeast Asia member countries are leveraging the possibilities of the digital economy while striving to improve stability at both the state and individual levels to cope with a variety of digital disruptions, with their rates of internet and social media penetration among the world's fastest-growing. The crisis mapper in Digital Humanitarian Networks collects all data from social media and plots it on a map to see who wants aid and where they need it. This term began when Patrick Meier, the first disaster mapper, used extremely scarce tools to chart the effects of the Haiti earthquake and save many lives in a critical span of time [9].

Table 1. Number of users of the internet, social mobile and social media

\begin{tabular}{ccccc}
\hline Southeast Asia Country & Total Population (mil) & Internet Users (mil) & Social Media Users (mil) & Mobile Social Users (mil) \\
\hline Indonesia & 268.2 & 150 & 150 & 130 \\
Philippine & 107.34 & 76 & 76 & 72 \\
Vietnam & 96.96 & 64 & 62 & 58 \\
Thailand & 69.24 & 57 & 51 & 49 \\
Malaysia & 32.25 & 25.28 & 25 & 24 \\
Singapore & 5.83 & 4.92 & 4.6 & 4.2 \\
\hline
\end{tabular}

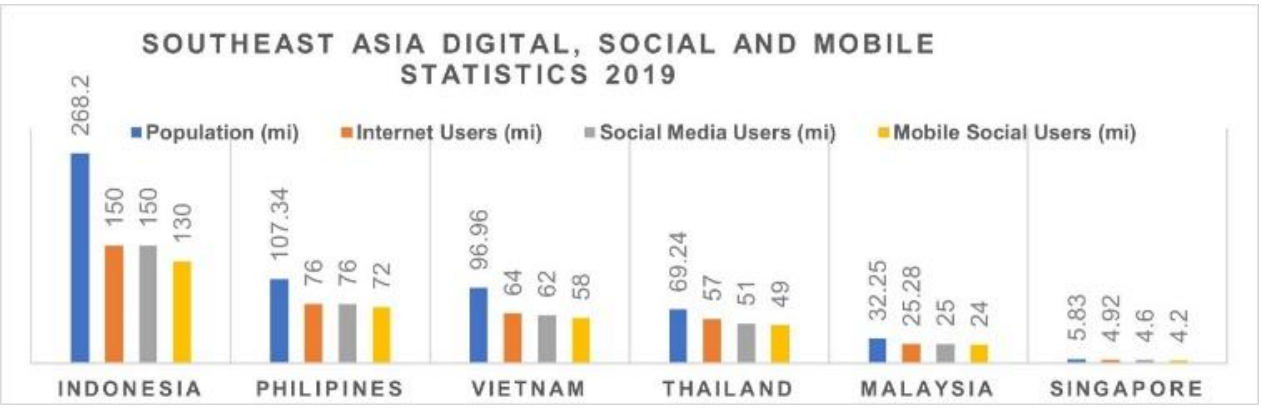

Figure 9. Social media and mobile usage in Southeast Asia for 2019 (Digital ASEAN Statistics, 2019) Source: Adapted from Digital ASEAN Statistics, 2019
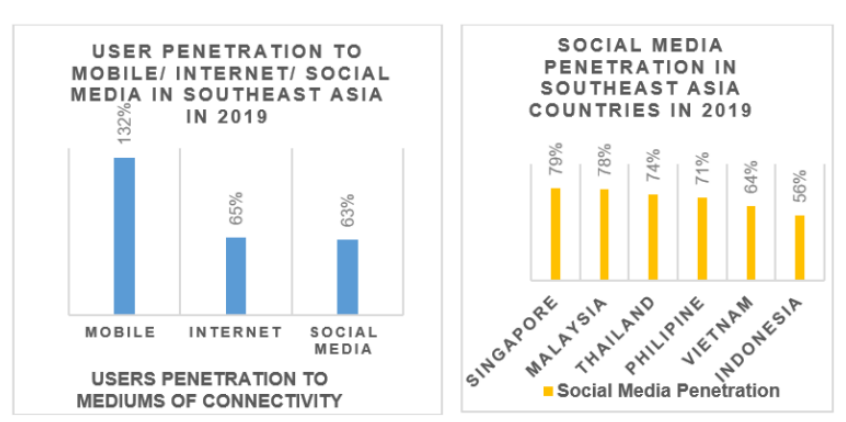

Figure 10. Penetration of mobile and social media in Southeast Asia (Digital ASEAN Statistics, 2019)

Source: Adapted from Digital ASEAN Statistics, 2019

After literation review and document analysis, the researcher comes up with some factors important in the southeast Asian countries for their readiness level. Using social media platforms for DRR activities, which are in practice or under research, any country can easily acquire DHN for crisis or disaster management through these factors. Some main factors contribute to the readiness of the use of social media for DRR in Southeast Asia. Mainly they are, Crowd Sourcing, Mobilise Social Users, Crisis mapping through GIS, Big Data \& IoT systems, Multi-Agency
Collaboration, and social media itself. Figure 11 shows the following factors deducted from the literature review and document analysis.

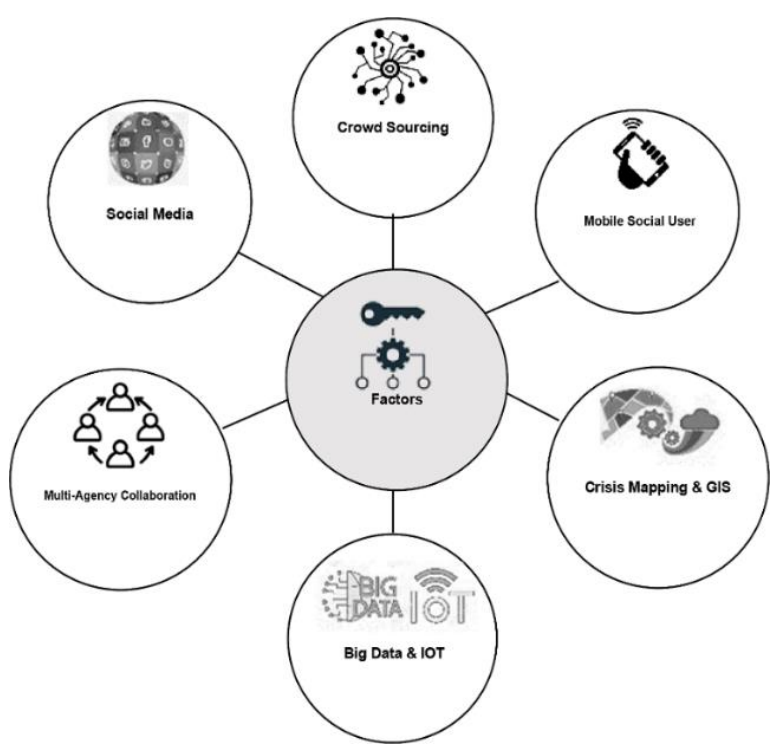

Figure 11. Factors for the readiness of the usage of DHN in Southeast Asia. Source: The Researcher, 2021 


\section{CONCLUSION}

Integrating social media and crisis management is inevitable because of the community's excessive use of social media apps and platforms in everyday life. Additionally, these social apps are two-way communication, including all kinds of information. If we perceive social usage constructively and optimistically, the members of community are considered resilient, self-collaborating and intelligent [44]. Furthermore, there are so many features of social media application usage for crisis management during disaster events that are not yet explored. Most notably are the behavioural experiences, beliefs and uses of social media [45]. The excessive use of social media in Southeast Asia makes utilising that information and useful data for disaster risk reduction inevitable. There are several ways to make use of that data for crisis management. Crisis mapping is one of them to plot all the data of the vulnerable community and assets to help the public and the organisations providing help to the victims. After mapping, DHN provides a collaborative environment for the organizations to collaborate and act fast to provide assistance. There are V\&TC teams associated with them to speed up the process. Southeast Asia is the most vulnerable area in the whole world, there are few activations of DHN in some countries in this area. Through which, they provide the speedy response activities, and the data is very helpful to provide assistance to the organisation and community.

In an emergency, the coordination bodies or a coordination network played a critical role in enhancing individual networks' overall success. However, it has been seen that every voluntary and technical community has its strength and weakness. In addition, to ensure the organisation continues and improves its capacity, competition is essential for the coordination bodies. In the case of Haiti experience, competition between the coordination networks can lead to a significant redundancy, and lack of coordination between the management caused the overall efficiency and success of the digital humanitarian system.

The objective of the digital humanitarian system is to reduce the conflict between the V\&TCs and already established systems. The success of DHN also depends upon the streamlines, relationship and connection between DHN organisations and V\&TCs that will allow to thrive and improve the network without disturbing any system. The successful DHN practices propose the same opportunities for their networks, implying other work domains where overlying roles create problems. However, determining a contract to be aligned can also be a big task and demands careful attention and consideration of governance, voice, and decision-making to be sustainable.

It is also very important for the community's empowerment to engage the participants, which ultimately increase the success of DHN. It is necessary to identify the challenges at the local level by involving international coordination, which provides a better solution that will support and facilitate grassroots initiatives. Network leaders, DHN professionals, the multi-agency collaborator will need to rethink how to solve problems best. Otherwise, they risk falling into the similar trap that many international organisations have faced previously by ensuring sustainable development could become more valuable than answering the problem. For future recommendations, DHN can be implemented throughout Southeast Asia during any disaster event as social media information can be very useful in this regard.

\section{ACKNOWLEDGMENT}

This research was supported by University of Salford, UK and Universiti Tun Hussein Onn Malaysia (UTHM), Malaysia [grant number A127 \& H376].

\section{REFERENCES}

[1] Alexander, D.E. (2014). Social media in disaster risk reduction and crisis management. Science and Engineering Ethics, 20(3): 717-733. https://doi.org/10.1007/s11948-013-9502-z.

[2] Sulaiman, N., Abid, S.K., Nazir, U., Mahmud, N.P.N., Latib, S.K.K.A., Hafidz, H.F.M., Ab Rahim, N. (2020). Need for resilience healthcare facilities management (RHFM) in Malaysia's public hospitals. A critical literature review. Proceedings of the International Conference on Industrial Engineering and Operations Management, p. 59.

[3] Abid, S.K., Sulaiman, N., Wei, C.S., Nazir, U. (2021). Building resilient future: Information technology and disaster management-a Malaysian perspective. In IOP Conference Series: Earth and Environmental Science, 795(1): $\quad 012026 . \quad$ https://doi.org/10.1088/17551315/795/1/012026.

[4] Sulaiman, N., She, T.W., Fernando, T. (2019). Community resilience frameworks for building disaster resilient community in Malaysia. Planning Malaysia, 17(9): 94-103. https://doi.org/10.21837/pmjournal.v17.i9.589.

[5] Janssen, M., Van Der Voort, H. (2020). Agile and adaptive governance in crisis response: Lessons from the COVID-19 pandemic. International Journal of Information Management, 55: 102180. https://doi.org/10.1016/j.ijinfomgt.2020.102180.

[6] Abid, S.K., Sulaiman, N., Mahmud, N.P.N., Nazir, U., Adnan, N.A. (2021). A review on the application of remote sensing and geographic information system in flood crisis management. J. Crit. Rev., 7(16): 491-496. https://doi.org/10.31838/jcr.07.16.58

[7] McCallum, I., Liu, W., See, L., Mechler, R., Keating, A., Hochrainer-Stigler, S., Moorthy, I. (2016). Technologies to support community flood disaster risk reduction. International Journal of Disaster Risk Science, 7(2): 198204. https://doi.org/10.1007/s13753-016-0086-5

[8] Milner, M. (2014). Global Solutions Networks - Digital Humanitarian Network, levering digital networks for humanitarian response - Lighthouse Cae Study," 29, http://gsnetworks.org/wp-content/uploads/DigitalHumanitarian-Network.pdf.

[9] Meier, P. (2012). Digital Disaster Response to Typhoon Pablo, National Geographic Society Newsroom, Dec. 2012.

https://blog.nationalgeographic.org/2012/12/19/digitaldisaster-response-to-typhoon-pablo/, accessed on May 29, 2021.

[10] Meier, P. (2015). Digital Humanitarians: How Big Data is Changing the Face of Humanitarian Response. Crc Press.

[11] Chan, J.C. (2012). The Role of Social Media in Crisis Preparedness, Response and Recovery. VanguardSingapure, http://www.oecd.org/governance/risk/The role of Social 
media in crisis preparedness, response and recovery.pdf.

[12] Maron, D. (2013). How social media is changing disaster response. Scientific American. https://www.scientificamerican.com/article/how-socialmedia-is-changing-disaster-response/, accessed on 16 May 2021.

[13] Blaikie, P., Cannon, T., Davis, I., Wisner, B. (2005). At risk: Natural hazards, people's vulnerability and disasters. Routledge. J. Homel. Secur. Emerg. Manag., 2014. https://doi.org/10.4324/9780203974575

[14] Pearson, L., Pelling, M. (2015). The UN Sendai framework for disaster risk reduction 2015-2030: Negotiation process and prospects for science and practice. Journal of Extreme Events, 2(01): 1571001. https://doi.org/10.1142/S2345737615710013

[15] Gupta, S. (2010). Synthesis Report on Ten ASEAN Countries Disaster Risks Assessment ASEAN Disaster Risk Management Initiative. https://doi.org/10.13140/RG.2.2.32014.36160

[16] Kurniawan S., Shea, W. (2018). Vol 40-Total Reported Natural Disaster in Southeast Asia., 2018. https://thecolumn.ahacentre.org/posts/insight-posts/vol40-total-reported-natural-disaster-in-shouteast-asia/, accessed on May 28, 2021.

[17] Abid, S.K., Sulaiman, N., Wei, C.S., Nazir, U. (2021). Flood vulnerability and resilience: Exploring the factors that influence flooding in Sarawak. In IOP Conference Series: Earth and Environmental Science, 802(1): 012059 .

$1315 / 802 / 1 / 012059$

[18] AHA Centre. (2020). Unfolding future: One ASEAN one response Annual report 2019. The AHA Centre.

[19] Thomalla, F., Boyland, M., Calgaro, E. (2017). Disasters and development in Southeast Asia Toward equitable resilience and sustainability. In Routledge Handbook of Southeast Asian Development, 342-361.

[20] Dette, R. (2018). Do No Digital Harm: Mitigating Technology Risks in Humanitarian. Technologies for Development: From Innovation to Social Impact, 13.

[21] Smitheman, M. (2013). Big Data: A Natural Solution for Disaster Relief, SmartData Collective, 2013.

[22] Skuse, A., Brimacombe, T. (2014). Social networking, social media and complex emergencies: Issues paper. Australian Government.

[23] World Bank. (2017). Philippines Lessons Learned from Yolanda: An Assessment of the Post-Yolanda Short-and Medium-Term Recovery and Rehabilitation Interventions of the Government. World Bank.

[24] Iacucci, A. (2015). Typhoon Yolanda - Update \#1, 2015. https://standbytaskforce.https//wordpress.com/2013/11/ 11/typhoon-yolanda-update-1/, accessed on May 29, 2021.

[25] Thompson C., Graham, C. (2015). Nepal Earthquake 2015 , HumanityRoad, 2015. https://www.humanityroad.org/case-studies/nepalearthquake-2015, accessed on May 29, 2021.

[26] Martini, B. (2015) Nepal earthquake emergency: Why digital humanitarian response matters and how you can help. https://beatricemartini.it/blog/nepal-earthquake/, accessed on May 29, 2021.

[27] Quarantelli, E.L. (1997). The Disaster Research Center (DRC) field studies of organized behavior in the crisis time period of disasters. Int. J. Mass Emerg. Disasters, 15(1): 1997.
[28] Velev, D., Zlateva, P. (2012). Use of social media in natural disaster management. Intl. Proc. of Economic Development and Research, 39: 41-45. https://doi.org/10.7763/IPEDR

[29] Sulaiman, N., Abid, S.K., Chan, S.W., Nazir, U., Mahmud, N.P.N., Latib, S.K.K.A., Fernando, T. (2020). Geospatial dashboards for mapping and tracking of novel coronavirus pandemic. Proceedings of the International Conference on Industrial Engineering and Operations Management, 59.

[30] Boulos, M.N.K., Resch, B., Crowley, D.N., Breslin, J.G., Sohn, G., Burtner, R., Chuang, K.Y.S. (2011). Crowdsourcing, citizen sensing and sensor web technologies for public and environmental health surveillance and crisis management: Trends, OGC standards and application examples. International Journal of Health Geographics, 10(1): 1-29. https://doi.org/10.1186/1476-072X-10-67

[31] Houston, J.B., Hawthorne, J., Perreault, M.F., Park, E.H., Goldstein Hode, M., Halliwell, M.R., Griffith, S.A. (2015). Social media and disasters: A functional framework for social media use in disaster planning, response, and research. Disasters, 39(1): 1-22. https://doi.org/10.1111/disa.12092

[32] Imran, M., Elbassuoni, S., Castillo, C., Diaz, F., Meier, P. (2013). Extracting information nuggets from disasterRelated messages in social media. In Iscram.

[33] Paul, A. (2015). Identifying relevant information for emergency services from twitter in response to natural disaster. Doctoral dissertation, Queensland University of Technology.

[34] Krimsky, S. (2007). Risk communication in the internet age: The rise of disorganized skepticism. Environmental Hazards, $\quad 7(2)$ : 157-164. https://doi.org/10.1016/j.envhaz.2007.05.006

[35] Cheong, M., Lee, V.C. (2011). A microblogging-based approach to terrorism informatics: Exploration and chronicling civilian sentiment and response to terrorism events via Twitter. Information Systems Frontiers, 13(1): 45-59. https://doi.org/10.1007/s10796-010-9273-x

[36] White, C., Plotnick, L. (2010). A framework to identify best practices: Social media and Web 2.0 technologies in the emergency domain. International Journal of Information Systems for Crisis Response and Management (IJISCRAM), 2(1): 37-48. https://doi.org/10.4018/jiscrm.2010120404

[37] Hughes, A.L., Palen, L. (2009). Twitter adoption and use in mass convergence and emergency events. International Journal of Emergency Management, 6(3-4): 248-260. https://doi.org/10.1504/IJEM.2009.031564

[38] Lindsay, B.R. (2011). Social media and disasters: Current uses, future options, and policy considerations. Congr. Res. Serv., 2011.

[39] Song, X., Yan, X. (2012). Influencing factors of emergency information spreading in online social networks: A simulation approach. Journal of Homeland Security and Emergency Management, 9(1): https://doi.org/10.1515/1547-7355.1979.

[40] Plotnick, L., White, C., Plummer, M.M. (2009). The design of an online social network site for emergency management: A one stop shop. AMCIS 2009 Proceedings.

[41] Reuter, C., Marx, A., Pipek, V. (2012). Crisis management 2.0: Towards a systematization of social 
software use in crisis situations. International Journal of Information Systems for Crisis Response and Management (IJISCRAM), 4(1): 1-16. https://doi.org/10.4018/jiscrm.2012010101

[42] Sutton, J.N., Palen, L., Shklovski, I. (2008). Backchannels on the front lines: Emergency uses of social media in the 2007 Southern California Wildfires.

[43] Sulaiman, N. (2012). The elderly and the provision of residential care homes for the elderly (RCHfE). University of Salford, Salford, Manchester.

[44] Gao, H., Wang, X., Barbier, G., Liu, H. (2011).
Promoting coordination for disaster relief-from crowdsourcing to coordination. In International Conference on Social Computing, Behavioral-Cultural Modeling, and Prediction, 6589: 197-204, https://doi.org/10.1007/978-3-642-19656-0_29

[45] Armstrong, C.L., McAdams, M.J. (2009). Blogs of information: How gender cues and individual motivations influence perceptions of credibility. Journal of Computer-Mediated Communication, 14(3): 435-456. https://doi.org/10.1111/j.1083-6101.2009.01448.x 